\title{
ESTUDIOS
}

\section{Regulación del sector financiero y separación de poderes'}

\section{Manuel Rodríguez Portugués ${ }^{2}$}

Resumen: El principio de separación de poderes, cuyo fundamento clásico reside en la garantía de la libertad de los ciudadanos, ha ido mutando conforme a los cambios históricos, desde una visión puramente institucional hasta otra más rica en la que también se tiene en cuenta la idea de equilibrio y contrapeso entre intereses sociales y económicos. En el contexto de ese proceso cobra especial relieve el nacimiento y propagación, dentro de los Estados democráticos constitucionales contemporáneos, de las denominadas autoridades independientes. Sin embargo, la influencia de poderosos intereses económicos y la fagocitación de las instituciones por el denominado Estado de partidos son susceptibles de afectar negativamente al buen funcionamiento de dichos organismos. Para lograr que el principio de separación de poderes continúe respondiendo a su vocación originaria de servicio a la igual libertad de los ciudadanos, el diseño de las autoridades independientes debe respetar una serie de requisitos. Finalmente, en el estudio se aplican dichas ideas a los actuales procesos de reordenación financiera y el organismo encargado de ellos, el Fondo de Reestructuración Ordenada Bancaria (FROB).

Palabras clave: Separación de poderes, reglamentación del sector financiero, Estado de partidos, FROB.

Fecha de recepción: 18 de enero de 2017.

Fecha de admisión: 9 de junio de 2017.

\footnotetext{
' Trabajo realizado en el marco del Proyecto de Investigación DER2015-67695-C2-2-P /MINECO/ FEDER.

${ }^{2}$ Facultad de Derecho y Ciencias Económicas y Empresariales, Universidad de Córdoba.
} 


\section{The regulation of the financial sector and separation of powers}

Abstract: The principle of separation of powers, the classic foundation of which rests in the guarantee of the citizens' freedom, has mutated according to the historic changes, from a vision merely institutional up until another richer, in which the idea of balance and counterweight between social and economic interests is taken into account.

In the context of that process, the birth and propagation within the contemporary constitutional and democratic States, gains special prominence.

However, the influence of powerful economic interests, and the gobbling up of the institutions by the so called Parties' State, are capable of negatively affecting the good functioning of the said organisms.

To achieve that, the principle of separation of powers continue to respond to its original vocation of service to the equal freedom of the citizens, the design of the independent authorities must respect a series of requirements. Finally, the said ideas are applied to the actual processes of financial reordering and to the organism in charge of them: the Fund of Ordered Bank Restructuring (FROB, for its Spanish acronym).

Keywords: Separation of powers, regulation of the financial sector, Political Parties State, FROB.
Réglementation du secteur financier et séparation des pouvoirs

Résumé: Le principe de la séparation des pouvoirs, dont le fondement classique réside sur la garantie de la liberté des citoyens, a muté au fur et à mesure des changements historiques, en passantd'une vision purement institutionnelle à une vision plus riche dans laquelle sont pris en compte l'idée d'équilibre et de contrepoids entre les intérêts sociaux et économiques.

Dans le contexte de ce processus, la naissance et la propagation des dénommées autorités indépendantes prend une importance particulière au sein des États démocratiques constitutionnels contemporains.

Cependant, I'influence de puissants intérêts économiques et le fait que les institutions soient phagocytées par ce que l'on entend comme "État de partis» peuvent avoir une influence négative sur le bon fonctionnement de ces organismes.

Pour que le principe de séparation des pouvoirs continue de répondre à sa vocation originelle de service à l'égale liberté des citoyens, la conception des autorités indépendantes doit respecter une série de critères. Finalement, ces idées sont appliquées au processus actuels de réaménagement financiers ainsi qu'au «Fond de restructuration ordonnée bancaire» (FROB).

Mots clé: Séparation des pouvoirs, réglementation du secteur financier, État de partis, FROB. 


\section{Introducción}

La crisis financiera internacional desatada en 2008 ha supuesto el despliegue de un proceso de reestructuración bancaria y financiera del que, al menos en España, todavía no se ve claramente el final. Dicha crisis ha llegado en un momento -y en gran medida precisamente por ello- en el que los mercados financieros estaban intensamente globalizados ${ }^{3}$. En el caso español, además, el sector bancario y crediticio estaba y está inmerso en un escenario de gran interdependencia en el ámbito regional europeo. Por eso, la influencia de las instituciones europeas ha sido intensa en cuanto a las medidas previstas y ha conducido a que su aplicación se confíe en cada Estado miembro a una nueva autoridad administrativa con poderes suficientes para imponerlas.

En España esa autoridad es el Fondo de Reestructuración Ordenada Bancaria (FROB), cuyos poderes van más allá de las clásicas técnicas de intervención administrativa de empresas en crisis. Sus potestades se proyectan directamente sobre las relaciones jurídicas y económicas entabladas entre multitud de sujetos privados (entidades, accionistas, inversores, depositantes...), es decir, impactan directamente sobre una materia que tradicionalmente estaba reservada al poder judicial (fundamentalmente, por la institución del concurso de acreedores).

La actual reestructuración bancaria plantea, por tanto, sugestivos interrogantes desde la perspectiva de la separación de los poderes del Estado. ¿2Hasta qué punto pueden atribuirse unos poderes tales a una autoridad administrativa, que, en definitiva, depende del poder ejecutivo, del Gobierno? ¿Es ello compatible con los postulados del Estado social de derecho? ¿Qué requisitos debe reunir una autoridad como el FROB para que los procesos de reestructuración bancaria resulten admisibles desde tal perspectiva?

Estos interrogantes no son indiferentes. En la respuesta que reciban se juega la libertad y la igualdad de los ciudadanos. Pero, a su vez, para responderlos cabalmente es preciso ahondar en los motivos que condujeron a formular en la teoría y a establecer en la práctica el principio de separación de poderes, cuáles han sido las transformaciones en su significado hasta la actualidad y cuáles son los principales fenómenos sociales y económicos a los que se enfrenta hoy.

\footnotetext{
${ }^{3}$ Sobre la génesis y las implicaciones financieras de la crisis, cfr. $M^{a}$. C. López MARTín y A. Rodero
} FRANGANILLO (2009). 


\section{Los perfiles clásicos de la separación de poderes}

\section{I. Separación de poderes, garantía de la libertad}

El constitucionalismo como forma de ordenar la convivencia política moderna se levanta sobre una serie de pilares teóricos bien conocidos: la afirmación de la soberanía popular, el reconocimiento de derechos y libertades fundamentales, el principio mayoritario como criterio para la adopción de decisiones, la justicia constitucional, etc. Quizá uno de los principios más importantes sea el de la separación de poderes.

Frente a otros principios, cuyos orígenes pueden rastrearse con claridad en tradiciones anteriores, el de separación de poderes es una formulación típicamente moderna, propia de la actitud que sitúa la reflexión filosófico-política sobre la política en torno a la dialéctica entre poder y libertad ${ }^{4}$. En efecto, cuando se postuló la separación de poderes -la distribución del poder entre distintas manos- no se formulaba un criterio para organizar el poder como otro cualquiera. Cuando se exigió la separación de poderes, se hizo con la intención explícita de evitar con ella toda forma de gobierno despótico, e instaurar y preservar así una forma de convivencia en la que los ciudadanos gozaran de una libertad equivalente en el estado civil o político a la que gozaban como individuos en el "estado de naturaleza".

Sin embargo, la separación de poderes-sobre todo la separación entre el legislativo y el judicial- puede verse como una garantía también de la igualdad. En efecto, el que la determinación "abstracta" de los derechos sea hecha por el cuerpo político, pero que la determinación "concreta" de ellos sea realizada por un órgano distinto, independiente e imparcial, tiene la finalidad de asegurar, también en lo concreto, la igualdad de los ciudadanos.

En cualquier caso, la estrechísima ilación entre separación de poderes y garantía de la libertad es patente desde los primeros autores que formularon teóricamente aquel principio. John Locke en su Segundo Tratado sobre el Gobierno Civil subrayaba cómo "el fin principal de los hombres al entrar en

\footnotetext{
${ }^{4}$ Aunque también goza de ciertos precedentes teóricos medievales. Para una evolución de las ideas políticas hasta la teoría de la separación de poderes, vid. S. MuÑOz MACHADO (2015), 12-22, que examina las aportaciones de autores como Bracton, Fortescue, Harrington, Coke y Blackstone, además de Locke y Montesquieu, que son los más conocidos.
} 
sociedad es disfrutar de sus propiedades en paz y seguridad" ${ }^{5}$ y cómo -por eso mismo- siempre

que los legisladores tratan de arrebatar y destruir la propiedad del pueblo, o intentar reducir al pueblo a la esclavitud bajo un poder arbitrario, están poniéndose a sí mismos en un estado de guerra con el pueblo, el cual, por eso mismo, queda absuelto de prestar obediencia ${ }^{6}$.

Ciertamente, esta obra otorga al poder legislativo una supremacía indiscutible frente a los demás poderes ${ }^{7}$, y su separación del poder ejecutivo deriva más bien de la necesidad práctica de ejercer el poder en los amplios períodos en que la asamblea legislativa estaba disuelta ${ }^{8}$. Pero es indudable también que en el Segundo Tratado late un rechazo hacia cualquier acumulación de poder en unas únicas manos, como así se pone especialmente de relieve en algunos pasajes:

siempre que el poder legislativo (...) trate de acumular excesivo poder o de depositarlo en manos de cualquier otro (...) estará traicionando su misión?;

como, debido a la fragilidad de los hombres (los cuales tienden a acumular poder), éstos podrían ser tentados a tener en sus manos el poder de hacer las leyes y el de ejecutarlas para así eximirse de obedecer las leyes que ellos mismos hacen (...), es práctica común en los Estados bien organizados (donde el bien de todos es debidamente considerado) que el poder legislativo sea puesto en manos de diversas personas ${ }^{10}$.

La separación de poderes como garantía de la libertad y de los derechos de los ciudadanos luce con mayor claridad aún en la influyente obra Del Espíritu de las Leyes de Montesquieu:

Cuando el poder legislativo está unido al poder ejecutivo en la misma persona o en el mismo cuerpo, no hay libertad porque se puede temer que el monarca o el Senado promulguen leyes tiránicas para hacerlas cumplir tiránicamente. Tampoco hay libertad

\footnotetext{
5 J. LOCKE (1690), 166.

6 J. LOCKE (1690), 252. legislativo sobre el ejecutivo (185).

8 J. LOCKE (1690), 178 y 179.

9 J. LOCKE (1690), 252 y 253.

10 J. LOCKE (1690), 178 y 179.
}

7 J. LOCKE (1690), 183: "En todos los casos, mientras el gobierno subsista, el poder supremo será el legislativo; pues aquel que dicta leyes a otro debe ser necesariamente superior a éste". Esa superioridad se manifiesta, por ejemplo, en los controles que en otra parte de esta obra LOCKE reconoce a favor del 
si el poder judicial no está separado del legislativo ni del ejecutivo. Si va unido al poder legislativo, el poder sobre la vida y la libertad de los ciudadanos sería arbitrario, pues el juez sería al mismo tiempo legislador. Si va unido al poder ejecutivo, el juez podría tener la fuerza de un opresor. Todo estaría perdido si el mismo hombre, el mismo cuerpo de personas principales, de los nobles o del pueblo, ejerciera los tres poderes: el de hacer las leyes, el de ejecutar las resoluciones públicas y el de juzgar los delitos o las diferencias entre particulares ${ }^{11}$.

Paradójicamente, y como es sabido, la obra de Montesquieu no influyó tanto en los revolucionarios franceses como en los norteamericanos. De ahí que estas mismas ideas brillen también con mucha claridad en la obra de los llamados Founding Fathers de los Estados Unidos de América en términos que son inequívocos: todos admiten hasta cierto punto como algo esencial para preservar la libertad el ejercicio de los diversos poderes de forma independiente y diferenciada ${ }^{12}$.

No es de extrañar, en fin, que también en los trabajos que precedieron a la primera Constitución española, la de 1812, se refleje la misma convicción, la del aseguramiento o garantía de la libertad de los ciudadanos como la finalidad y el espíritu que anima el principio de separación de poderes:

No puede haber sociedad civil sin el ejercicio de los tres poderes, legislativo, ejecutivo y judicial, ni buen gobierno si estos tres poderes están reunidos en una sola persona. En el Estado donde esto sucede no hay más que señor y esclavos.

Así se expresaba el cuestionario presentado el 5 de noviembre de 1810 por Antonio Ranz Romanillos a la Junta de Legislación-constituida en el seno de las Cortes de Cádiz- de la que salió la decisión de elaborar y aprobar una Constitución para España ${ }^{13}$.

${ }^{11}$ C-L. S. B. de Montesquieu (1735), 107. Y un poco más adelante: "Si no hubiera monarca y se confiara el poder ejecutivo a cierto número de personas del cuerpo legislativo, la libertad no existiría, pues los dos poderes estarían unidos, ya que las mismas personas participarían en uno y otro" (111).

12 J. MADISON (1788), 397.

${ }^{13}$ Citado por M. ARTOLA (1999), 48 (p. XLVIII). 


\subsection{La separación de poderes como sistema de frenos y contrapesos en la tradición anglosajona}

Si el fundamento de la separación de poderes estuvo claro desde un principio -la libertad de los ciudadanos y su necesidad de preservarla de todo poder despótico-, no sucedió lo mismo en relación con el modo concreto de plasmar sus exigencias. Desde este punto de vista, en efecto, dicho entendimiento siguió una suerte muy distinta a un lado y otro del Atlántico, en el constitucionalismo norteamericano y en el francés.

Como se ha señalado, en el proceso constitucional estadounidense tuvo una influencia determinante la obra de Montesquieu. En ella, el autor francés insiste en que separación no es igual a incomunicación; más bien, se trata de lo contrario, de que el poder frene al poder. La idea de la que parte es de tipo empírico:

es una experiencia eterna que todo hombre que tiene poder siente la inclinación de abusar de él (...) Para que no se pueda abusar del poder es preciso que, por la disposición de las cosas, el poder frene al poder ${ }^{14}$.

Y así, partiendo del modelo -más idealizado que real- de la constitución inglesa del momento como tipo de constitución mixta, concreta esta idea describiendo qué mecanismos de relación deben existir entre los poderes legislativo, ejecutivo y judicial para que unos sirvan de freno y contrapeso de los otros (convocatoria y disolución de la asamblea legislativa por el ejecutivo, facultades de veto, control del ejecutivo por el legislativo, reserva de determinadas funciones judiciales al parlamento, etc. $)^{15}$.

Estas ideas son las que pasan a los artífices de la Constitución norteamericana. Y, en efecto, para estos autores la separación no es tampoco incomunicación, sino que se resuelve en una pléyade de mecanismos a través de los cuales el ejercicio de los poderes -sin que estos recaigan o se entremezclen en las mismas manos-

\footnotetext{
${ }^{14}$ C-L. S. B. de Montesquieu (1735), 106.

${ }^{15}$ Vid. C-L. S. B. de MONTESQUIEU (1735), 111-113. En LOCKE la idea del equilibrio entre los poderes a través de frenos y contrapesos no aparece ni mucho menos con tanta claridad. Así, el control al que queda sometido el ejecutivo por el legislativo (Segundo Tratado sobre el Gobierno Civil, 185) se debe en su pensamiento, más bien, a la supremacía del legislativo sobre los demás poderes, idea en torno a la que gira prácticamente todo el Segundo Tratado. Y, de forma similar, el poder de "prerrogativa" reconocido al ejecutivo frente al legislativo (actuar al margen de la ley o incluso contra ella en circunstancias excepcionales), no se fundamenta en la idea de equilibrio de poderes mediante frenos y contrapesos, sino en el principio "salus populi suprema lex" (191 y 192).
} 
resulta constantemente interferido por los otros a fin de esquivar el riesgo de un poder ilimitado o despótico, con perjuicio de la libertad. En el número 47 de El Federalista, atribuido a la pluma de Madison y titulado precisamente "Cómo concebir y aplicar el principio de la separación de poderes", se insiste en que la concepción de la separación de poderes de Montesquieu -al que se cita abundantemente- no quería expresar una ausencia total de intervención parcial en los actos de las otras ramas, o de control sobre ellas. Por eso, tras repasar los mecanismos de frenos y contrapesos entre poderes previstos en las distintas constituciones de los Estados federados, concluye estableciendo la necesidad de que las diversas partes constitutivas del gobierno mantengan a las demás en su sitio gracias a la relación que establecen unas con otras. Y así, a lo largo del importante número 51, se defienden y describen de forma general los abundantes frenos y equilibrios estructurales previstos en la Constitución federal.

\subsection{La separación como incomunicación en la tradición francesa-continental y su posterior evolución}

Las cosas fueron inicialmente muy distintas en el proceso constitucional-revolucionario francés. Allí, por circunstancias históricas bien conocidas, triunfó inicialmente una visión de la separación de poderes como incomunicación, como ausencia absoluta de interferencia entre ellos, $y$-además- con una fuerte deferencia hacia el poder legislativo, concentrado en una única cámara, la Asamblea nacional. Mientras que la desconfianza de los revolucionarios norteamericanos se proyectaba hacia el legislativo -por eso, entre otras cosas, lo configuraron como bicameral-, las prevenciones de los revolucionarios franceses se dirigían sobre todo al ejecutivo y al judicial. Más que Montesquieu, fue determinante la influencia de Rousseau, que tenía una concepción más "rígida o técnica" de la separación de poderes" Lo cierto es que, en las constituciones del período revolucionario, el principio de separación de poderes tuvo un reconocimiento puramente formal, en el sentido de que, frente a la preeminencia casi total del legislativo, el ejecutivo y el judicial experimentaron un debilitamiento muy intenso. En la primera Constitución, la de 1791, el veto -limitado temporalmente- del rey a las leyes de la Asamblea se introdujo no sin fuertes resistencias. Además, el ejecutivo carecía del poder de desarrollar las leyes de la Asamblea, función que quedaba reservada a ella misma. Por su parte, las competencias del poder judicial quedaban confinadas a la resolución de conflictos entre ciudadanos, sin control alguno sobre los actos del legislativo ni del ejecutivo.

${ }^{16}$ R. JIMÉNEZ Asensio (2016), 84-86 y 234. 
Las consecuencias de tal diseño no se dejaron esperar. Ante la presión externa experimentada por Francia, la Asamblea inició un rápido proceso de concentración del poder que culminará, a partir de 1793, con la creación del Comité de Salud Pública como órgano delegado suyo. El Comité, como "ejecutivo delegado" de la Asamblea, fue acrecentando su poder a través de medidas extraordinarias y en detrimento de la misma Asamblea. Se reorganizó la administración central, departamental y municipal, haciéndola depender de la discrecionalidad omnímoda del Comité, y se puso en vigor una forma de gobierno basada en el miedo y la arbitrariedad, inaugurándose así la etapa denominada, por ello mismo, "del Terror $^{\prime \prime 17}$. Se consumó quizá a la letra el peligro del que, muchos años antes, había advertido Montesquieu:

Si no hubiera monarca y se confiara el poder ejecutivo a cierto número de personas del cuerpo legislativo, la libertad no existiría, pues los dos poderes estarían unidos, ya que las mismas personas participarían en uno $y$ otro $^{18}$.

Tras los desmanes de esta etapa, la separación de poderes como incomunicación o principio meramente formal experimenta una tímida evolución, admitiéndose alguna fórmula de control y contrapeso del poder legislativo en la Constitución de 1795, como -por ejemplo- fue el diseño de un legislativo bicameral. Habrá que esperar, sin embargo, a que se cierre el paréntesis representado por el poder crecientemente despótico ejercido por Napoleón a partir del golpe de Estado de 1799, para que la separación de poderes vigente en el constitucionalismo francés se enriquezca con contenidos más sustantivos a lo largo del tortuoso siglo XIX.

\section{Mutación, enriquecimiento y nuevos desafíos del principio de separación de poderes}

Más o menos el mismo entendimiento de la separación de poderes que reinaba en el tránsito del antiguo al nuevo régimen en Francia, es el que se impuso en el constitucionalismo europeo continental ${ }^{19}$. Pero, al igual que en Francia, el curso de los acontecimientos históricos de los siglos XIX y XX ha hecho que el entendimiento del principio de separación de poderes experimente una mutación enriqueciéndose

17 Un resumen de este proceso en R. JIMÉNEZ Asensio (2016), 94-103.

${ }^{18}$ C-L. S. B. de Montesquieu (1735), 111.

${ }^{19}$ Vid. R. JiMÉnez Asensio (2016), 105-125. 
con nuevos contenidos. Algunas de estas mutaciones han sido comunes a las culturas constitucionales estadounidense y europea. Otras, por diversas circunstancias, han sido más bien exclusivas de esta.

\section{I. La inamovilidad de los jueces y la independencia del poder judicial}

La primera tiene que ver con el poder judicial. El tratamiento de este poder presentaba evidentes deficiencias en el primer constitucionalismo. Locke ni siquiera lo consideraba ${ }^{20}$, y Montesquieu lo reducía a ser la "voz de la Ley" y lo confinaba a los asuntos penales y civiles entre particulares, sin control alguno sobre los demás poderes, diseño que fue adoptado por la revolución francesa. Durante largo tiempo, el poder judicial no fue, ni en Francia ni en otros países europeos influidos por aquel, un auténtico poder, sino más bien una "administración" de justicia plenamente vinculada a la ley y orgánicamente dependiente del poder ejecutivo. En efecto, aunque protegidos los jueces por la inamovilidad, en Europa continental se asumió un modelo burocrático de juez, de forma que el acceso, promoción, retribuciones y sanciones dependían en lo esencial del Gobierno, concretamente de los respectivos ministerios competentes en la rama de justicia ${ }^{21}$.

Poco a poco, sin embargo, se consiguió, en el período que va desde finales del siglo XIX hasta la mistad del siglo XX, que el poder judicial controlara los actos del ejecutivo que afectaran a los derechos de los ciudadanos. Pero lo que durante largo tiempo continuó como asignatura pendiente era el modo de salvaguardar la independencia judicial, característica reputada, sin embargo, como esencial para la existencia de un auténtico sistema de separación de poderes. En los países europeos con un modelo burocrático de judicatura-Bélgica, Francia, Italia, Portugal, España...- la solución ha pasado por crear unos órganos constitucionales "ad hoc" de carácter colegiado, con funciones ejecutivas de autogobierno del poder judicial (sobre todo, promoción y disciplina de los jueces), de modo que dicho poder quede a salvo de las interferencias de los demás. En España ese órgano es el Consejo General del Poder Judicial, previsto en la Constitución de 1978, y

${ }^{20}$ El capítulo 12 del Segundo Tratado lleva por título "De los poderes legislativo, ejecutivo y federativo". Este último, en realidad, es parte de lo que hoy denominaríamos poder ejecutivo, pues era el poder de dirigir las relaciones exteriores del Estado. Y lo que después se denominaría poder judicial podría entenderse incluido como parte de lo que Locke trata como "poder ejecutivo", al que define como aquel que está siempre activo y que vigila la puesta en práctica de esas leyes [las aprobadas por el legislativo] y la aplicación de las mismas (179).

${ }^{21}$ Vid. R. JIMÉNEZ AsENSIO (2016), 122. 
cuyo funcionamiento -por la irrupción de lo que se ha venido a llamar "Estado de partidos"- presenta disfunciones notables, como luego se dirá.

\subsection{La emergencia de "otros poderes" constitucionales. En especial, los tribu- nales constitucionales}

Junto a los tres poderes "naturales" a los que se referían los constitucionalistas clásicos $^{22}$, han aparecido con el tiempo otros poderes $u$ órganos constitucionales distintos como respuesta a la necesidad de mejorar el control del poder, que es -al fin y al cabo- de lo que se trata con el principio de separación de poderes. A diferencia de lo acontecido en Estados Unidos, donde el control judicial de la constitucionalidad de las leyes quedó afirmado desde principios del siglo XIX, en Europa continental las cosas fueron muy distintas.

Ya hemos aludido a la preeminencia del legislativo en los sistemas de influencia francesa. Esa preeminencia significaba la supremacía de dicho poder sobre los demás, que quedaban en una posición absolutamente subordinada. Por ello, la ley, expresión máxima del poder legislativo, quedaba a salvo de todo control por parte de los demás poderes. Se vivió, así, un largo período en la cultura jurídica europea que se ha dado en llamar "legicentrismo" 23.

La principal consecuencia de este "legicentrismo" es que las Constituciones del siglo XIX y de parte del XX no pasaban de ser meras declaraciones políticas sin un especial valor jurídico vinculante. En efecto, sus disposiciones, tanto de carácter organizativo como en materia de derechos constitucionales, quedaban al albur de las redefiniciones que un legislativo sin frenos decidiera en cada momento. La factura que se terminó pagando fue muy cara, por lo que, una vez superadas las traumáticas experiencias totalitarias vividas en torno a la segunda guerra mundial, el constitucionalismo europeo se vio abocado a corregir los excesos del "legicentrismo" y someter a control también al legislativo, sobre todo para garantizar la subordinación y el respeto de éste hacia la constitución.

La respuesta que se dio a esta necesidad -no sin intensos debates académicos y políticos- fue la atribución del poder de controlar la constitucionalidad de las

22 J. MADISON (1788), 397: "Tras distinguir teóricamente las tres clases de poderes, que por naturaleza se dividen en poder legislativo, ejecutivo y judicial...".

${ }^{23}$ Según denominación acuñada por S. RIALS (1988). 
leyes no al poder judicial, sino a un órgano constitucional de nuevo cuño, la corte, tribunal o consejo constitucional, según las denominaciones al uso en cada país. Con el breve antecedente del Tribunal de Garantías Constitucionales previsto en la Constitución de 1931, en España la Constitución de 1978 ha creado el Tribunal Constitucional, una de cuyas funciones principales es el control de la constitucionalidad de las leyes a través de los recursos y mecanismos regulados en su Ley orgánica de 1979.

Pero además de con los tribunales constitucionales, los mecanismos de control del poder se han enriquecido con la aparición, también en los textos constitucionales y con su propio estatuto de independencia, de otros órganos de fiscalización. Los tribunales o cámaras de cuentas, así como los defensores del pueblo, se inscriben en esta órbita. El Consejo de Estado es, sin embargo, mucho más antiguo. Nació en Francia en 1799, con el propósito de paliar en algo la falta de control de los actos del ejecutivo. Con el tiempo se convirtió en el órgano encargado de resolver los recursos de los ciudadanos frente a dichos actos. Entre nosotros el Consejo de Estado es también un órgano de control del ejecutivo, pero con funciones meramente consultivas, ya que el control jurídico de los actos del ejecutivo a través de los correspondientes recursos está confiado desde antiguo -pero más plenamente desde 1956- a una rama especializada del poder judicial, la jurisdicción contencioso-administrativa.

\subsection{Los derechos fundamentales y los derechos sociales}

Otra necesidad fuertemente sentida en Europa después de la segunda guerra mundial fue la de proteger los derechos humanos dentro -no sólo, pero sí en primer lugar- de cada Estado. No bastaban, por tanto, los catálogos formulados como meras declaraciones de buenas intenciones, propias de la Francia de 1789 y del siglo XIX y parte del XX. A los derechos fundamentales había que dotarles de un sistema concreto de garantías para que fueran realmente eficaces $y$ ejercitables por los ciudadanos. Con ocasión de ello, el constitucionalismo de la segunda posguerra mundial profundizó en el concepto de derechos fundamentales, $y$, en concreto, se consideró a partir de entonces que estos derechos no son simples facultades subjetivas que preservan una esfera de libertad individual (de "Freiheitsphären" hablaban los juristas de formación kantiana ${ }^{24}$, oponiendo un límite meramente negativo frente a los poderes públicos.

${ }^{24}$ Vid. F. Carpintero Benítez (1989), 105. 
Muy al contrario, a partir de la Ley fundamental de Bonn (1949) se va extendiendo la convicción de que los derechos fundamentales disponen también, antes incluso que aquella subjetiva, de una dimensión objetiva según la cual son estos derechos los que dotan de sentido al poder, de forma que sin su garantía y protección no existe propiamente Estado constitucional. Los derechos fundamentales lo son también porque dotan de fundamento al entero orden constitucional. Los derechos, a partir de entonces, no sólo protegen frente al poder, sino que están en la base misma del funcionamiento de todo sistema de poderes y de la idea misma de Constitución. Así se expresa, por ejemplo y con fuerte influencia de la Ley fundamental alemana, la Constitución Española de 1978:

La dignidad de la persona, los derechos inviolables que le son inherentes, el libre desarrollo de la personalidad, el respeto a la ley y a los derechos de los demás son fundamento del orden político y de la paz social (artículo 10.1) (25. $^{25}$

Esta concepción de los derechos fundamentales, como orden axiológico de la misma convivencia social, guarda en su seno una fuerza expansiva que se proyectará casi al mismo tiempo en dos direcciones. La primera, hacia el reconocimiento paulatino de los derechos fundamentales no sólo frente al poder, sino también -con las oportunas modulaciones- frente a otros ciudadanos $u$ organizaciones sociales distintas de los poderes públicos. Es la denominada "eficacia horizontal" de los derechos fundamentales ${ }^{26}$. La segunda dirección en la que se movió la expansión de los derechos fundamentales es el de su disfrute efectivo por parte de todos los ciudadanos, sin que las desigualdades económicas y sociales pudieran erigirse como obstáculo para su goce pleno por todos. Es la cláusula del Estado social, según la cual los derechos no sólo constituyen límites negativos para el poder, sino que imponen también límites positivos, obligaciones de hacer que se traducen, la mayor parte de las veces, en la prestación de servicios públicos. Algunas de esas obligaciones accedieron a la condición de derecho fundamental en su máximo rango (entre nosotros, por ejemplo, el derecho a la educación); otras, sin embargo, han quedado configuradas en la Constitución más bien como "principios rectores" a merced de las determinaciones presupuestarias del gobernante de turno.

${ }^{25}$ Vid. R. JIMÉNEZ ASENSIO (2016), 192-197.

${ }^{26}$ Vid. R. JiMÉnez Asensio (2016), 196-197. 
3.4. Aparición y generalización de las autoridades o administraciones independientes en el llamado "Estado regulador"

Más reciente en el proceso evolutivo experimentado por el principio de separación de poderes es la irrupción de las denominadas autoridades o administraciones independientes. Históricamente surgen a finales del siglo XIX en Estados Unidos, pero no se generalizan en ese país hasta el transcurso del "New Deal". Algunas décadas después se introdujeron en los ordenamientos de la Europa continental y en ellos, y en el de la Unión Europea, han proliferado hasta adquirir carta de naturaleza.

Básicamente, son organismos públicos que, por diversas razones técnicas, económicas o jurídico-institucionales, se crean para ejercer las competencias que les atribuye el poder legislativo pero fuera del área de influencia o al margen de la dirección del poder ejecutivo. El régimen jurídico de estos entes está precisamente configurado con la intención explícita de asegurar y garantizar dicha independencia. Entre nosotros goza de esta condición, por ejemplo, el Banco de España, la Comisión Nacional del Mercado de Valores, la Autoridad Independiente de Responsabilidad Fiscal, el Consejo de Transparencia y Buen Gobierno, la Comisión Nacional de los Mercados y de la Competencia, la Agencia Española de Protección de Datos, etc.

Tanto en Estados Unidos como en Europa, el debate sobre este tipo de organismos ha girado en torno a su difícil compatibilidad con el principio tradicional de separación de poderes. Efectivamente, como hemos visto, salvo los casos expresamente previstos por la misma Constitución (consejos de Estado, cortes constitucionales, etc.), el citado principio exige que todas las funciones públicas sean reconducidas a alguno de los tres poderes clásicos. Pero hay que convenir con Jiménez Asensio en que el verdadero problema no reside en esta cuestión. Tal enfoque es excesivamente formal y no presenta dificultades especiales habida cuenta de la flexibilidad evolutiva exhibida por el principio de separación de poderes a lo largo de la historia del constitucionalismo. El verdadero problema radica en si la creación de las autoridades independientes camina en la dirección correcta, es decir, si sirve para incrementar en términos cualitativos el control del poder por el poder-donde reside la esencia de la separación de poderes-, o por el contrario constituye un subterfugio para huir de dicho sistema de controles ${ }^{27}$.

El diseño de cada autoridad independiente ha de ser expresión, por tanto, de un equilibrio institucional, no siempre fácil de conseguir, entre dos polos en tensión: el desarrollo de las competencias del ente con el grado de independencia y ob-

${ }^{27}$ Vid. R. JIMÉNEZ AsENSIO (2016), 213. 
jetividad técnica requerido por la índole de las funciones atribuidas, por un lado, y la responsabilidad y el necesario control de tal ejercicio, por otro. También en relación con estas autoridades independencia no significa -no debe significarincomunicación o aislamiento. También aquí un poder sin responsabilidad sería, lógicamente, un poder ilimitado, arbitrario y sin sentido en el marco de un Estado de derecho, aunque sólo se proyectara sobre un sector socioeconómico concreto. Pero esa responsabilidad, a su vez, no debería traducirse en controles tan intensos que colocaran a la autoridad en una posición de subordinación tal que arruinara el espacio de independencia que se ha querido abrir con su creación.

Por otro lado, suele decirse que el fenómeno de las autoridades independientes se caracteriza por afectar, de entre los poderes clásicos, al ejecutivo, puesto que con su creación lo que el legislativo hace es resituar funciones atribuidas a aquel en estos nuevos organismos especializados ${ }^{28}$. No es cierto del todo. En ocasiones, la atribución de determinadas competencias a algunas autoridades independientes, más que a las atribuciones tradicionales del ejecutivo, afecta a las del poder judicial.

Recordemos que desde los tratadistas clásicos, como Locke o Montesquieu, pasando por las experiencias constitucionales posteriores, las atribuciones del poder judicial quedaban circunscritas típicamente, además de al enjuiciamiento de los delitos (justificado en que las penas eran habitualmente la muerte o la privación de libertad o del patrimonio necesario para llevar una vida independiente), a la resolución de litigios entre ciudadanos, es decir, a la resolución de controversias en las que se jugaban los derechos de un sujeto privado contra otro. Pues bien, existen casos de autoridades independientes creadas con la finalidad de ejercer este tipo de atribuciones. Actualmente, un ejemplo de este tipo de administración independiente en España es el de la Agencia Española de Protección de Datos. Se trata, en efecto, de una autoridad independiente del poder ejecutivo cuya principal atribución consiste en hacer valer el derecho fundamental a la protección de datos personales de un ciudadano frente a la lesión o ataque provocado por otro particular, normalmente una empresa $u$ otro tipo de organización privada. El caso es ciertamente singular, porque no nos encontramos aquí ante lesiones de un derecho privado cualquiera, sino ante ataques a un derecho fundamental. Pero repárese en que la Agencia está actuando en estos casos como un tercero ajeno a la disputa en cuestión, disputa que es entablada entre dos particulares. La posición de la Agencia es, desde este punto de vista, sustancialmente igual a la del poder judicial. Así sucede, por ejemplo, cuando un particular exige de una empresa que cancele los datos personales que conserva de él y deje de tratarlos con fines

${ }^{28}$ Vid. R. JIMÉNEZ AsENSIO (2016), 213. 
comerciales o publicitarios. Si la empresa hace caso omiso a dicha petición, el afectado tiene fundamentalmente dos opciones: o acudir a los órganos del poder judicial demandando la correspondiente tutela frente a la empresa; o poner una denuncia ante la Agencia Española de Protección de Datos para que sea ésta la que, tras el procedimiento oportuno, restablezca al particular en su derecho frente a la empresa. Esta segunda opción es en sustancia equivalente a la primera, pero con una ventaja clara: el procedimiento es más rápido y barato.

En mi opinión, para que la atribución administrativa de funciones jurisdiccionales como es la resolución imperativa de diferencias entre particulares- resulte compatible con el principio de separación de poderes, han de concurrir dos requisitos: primero, que en ese tipo de conflictos haya un interés general, más allá del interés meramente privado de las partes enfrentadas ${ }^{29}$ (por ejemplo, en el ámbito financiero-por poner un caso del sector en el que nos vamos a detener después- el interés general en la rápida intervención y reestructuración de una entidad financiera que puede poner en riesgo el equilibrio del sistema); $y$, segundo, que desde el punto de vista organizativo la autoridad administrativa competente ofrezca unas garantías de independencia e inamovilidad sustancialmente equivalentes a las ofrecidas por el poder judicial ${ }^{30}$.

Por lo que se refiere al primer requisito, poco puede decirse sino que la concurrencia del interés general habrá de ser inferida de las circunstancias concretas del sector socioeconómico sobre el que se proyecten las competencias de la autoridad y el tipo de problemas que con su creación tratan de paliarse.

En cuanto al segundo requisito, la independencia e inamovilidad de estas autoridades, como se ha dicho, no puede ser absoluta. De ahí que los nombramientos de sus órganos directivos (director, presidente, etc.) correspondan al poder legislativo o al ejecutivo o a ambos conjuntamente. Además, sus decisiones son, evidentemente, recurribles ante el poder judicial. Pero, si no absoluta, la independencia debe ser real, de modo que una nota característica esencial del régimen de estas autoridades es que los titulares de dichos órganos, una vez nombrados, no cesan sino por el trascurso del tiempo legalmente previsto para su mandato (normalmente plazos más amplios que los de las legislaturas en las que han sido nombrados) y sólo pueden ser cesados por causas tasadas y graves, así mismo previstas en la ley con carácter general ${ }^{31}$.

29 Vid. M. Rodríguez Portugués (2013).

${ }^{30}$ En este sentido, A. Bueno Armijo (2014).

${ }^{31}$ A su vez, el ámbito de independencia de estas autoridades administrativas se ha tratado de preservar frente al poder judicial exigiendo que el control judicial de sus decisiones se ciña estrictamente a los 


\section{El plano social, más allá del institucional, del principio de separación de poderes}

Pero las mutaciones del principio de separación de poderes no se agotan en esto. Algo sobre lo que no se suele llamar la atención es que, en el programa político clásico ilustrado, al menos en el que se explicita por los autores norteamericanos, la idea de separación se mueve o se proyecta en un plano que va más allá del meramente formal o institucional de los poderes del Estado. En efecto, en el ideal ilustrado la emancipación del individuo es emancipación de todo poder opresor, no sólo del poder estatal una vez se ha accedido al estado civil. Es más, la instauración misma del poder del Estado se justifica como remedio o protección frente al poder arbitrario de unos hombres sobre otros. La desconfianza de los constitucionalistas clásicos se proyectaba hacia el poder, hacia toda forma de poder, público o no. El poder no es un dato más de la realidad, sino algo esencialmente peligroso, de lo que hay que desconfiar por principio. De ahí, en definitiva, que algunos de los teóricos clásicos de la separación de poderes como sistema de frenos y contrapesos también dirigieran su mirada al poder propio del "estado de naturaleza", es decir, a los poderes no estatales reinantes en la sociedad, para postular asimismo su fragmentación a fin de impedir su conversión, merced a su acaparamiento, en una amenaza para la libertad.

De nuevo, son muy ilustrativas a este respecto las siguientes palabras de Madison:

En una república es muy importante que se proteja no sólo a la sociedad de los abusos que puedan cometer sus gobernantes, sino también a una parte de la sociedad contra las injusticias que puedan perpetrar otros segmentos de la misma. Entre las diversas clases de ciudadanos hay necesariamente intereses diversos. Si una mayoría se une en torno a ciertos intereses comunes, esto supondrá una amenaza para los intereses de la minoría. (...) En una sociedad estructurada de tal modo que una facción poderosa puede fácilmente unirse para oprimir a la parte más débil, se puede decir que reina tan libremente la anarquía como en el estado de naturaleza, donde no hay seguridad alguna para el más débil ante la fuerza del más poderoso ${ }^{32}$.

Esta perspectiva, que los "Founding Fathers" no desarrollaron con detalle, ha sido retomada por constitucionalistas norteamericanos recientes, como Daryl J. Levinson,

aspectos de pura legalidad, sin que los jueces y tribunales puedan entrar en las apreciaciones técnicas contenidas en las decisiones de estas autoridades. Una crítica a esta excesiva deferencia del poder judicial hacia las autoridades independientes, que -sin embargo- se ha ido corrigiendo parcialmente con el tiempo, puede verse en G. ARIÑO OrTIZ (2010).

32 J. MADISON (1788), 400 y 401.

Revista de Fomento Social 72/2 (20|7) 
quien incluso ha llegado a afirmar que la misma separación de poderes (además del federalismo) fue concebida originalmente más bien como mecanismo para contrapesar el poder entre intereses y grupos sociales ${ }^{33}$.

Este autor ha llamado la atención sobre la necesidad de ampliar el enfoque, desde una perspectiva exclusivamente institucionalista del Derecho público, hacia la búsqueda y localización de los poderes realmente existentes en la sociedad. Así, por ejemplo, señala que el poder de las instituciones no sólo depende de las disposiciones constitucionales o legales, sino también de diversas formas fácticas de poder y de influencias. Para aseverar esta afirmación se refiere al caso del presidente de los Estados Unidos, que hoy tiene un poder efectivo que está por encima del que se deriva de la letra de la Constitución. Indica que dicho incremento de poder ha sido consecuencia de un proceso más o menos largo en el que han tenido mucho que ver factores como el incremento del poder federal en detrimento del estatal, los modernos métodos de comunicación para presionar a los otros poderes públicos a través de la opinión pública y el fortalecimiento del sistema de partidos, que crea una tupida red de lealtades fácticas, por debajo de lo formalmente declarado o formulado en la Constitución ${ }^{34}$.

\section{I. El "Estado de partidos"}

En relación con esto último, Levinson pone el dedo en una de las llagas más dolorosas que aqueja a muchas democracias, incluida la nuestra. Se puede definir el "Estado de partidos", expresión acuñada en Alemania en el siglo XX, como aquel sistema político en el que los partidos -tras una larga evolución desde los inicios del Estado liberal-, lejos de contentarse con el desarrollo de sus funciones en el seno del marco institucional que les es propio, tienden a apropiarse de las instituciones y a confundirse con ellas, hasta el punto de que éstas quedan totalmente colonizadas o fagocitadas por aquéllos.

Los factores que han contribuido a tal estado de cosas son muy variados y complejos. Por ejemplo si la profesionalización de los integrantes del partido alcanza cotas de gran intensidad, la pérdida del poder supone la interrupción del flujo de beneficios o recursos disponibles para las "clientelas". Ello ha provocado, en tales casos, que los partidos políticos se conviertan cada vez más en formidables

${ }^{33}$ D. J. LEVINSON (2016), 83.

${ }^{34}$ D. J. LEVINSON (2016), 74. 
maquinarias electorales con el único fin de obtener el poder al precio que sea. Con ello, además, se produce otro fenómeno: los partidos políticos han ido dejando de ser parte de la sociedad, perdiendo el contacto con ella, para convertirse cada vez más en "parte del Estado"35.

Las consecuencias de todo ello para el buen funcionamiento de las instituciones son evidentes. En algunos países, como en el nuestro, la relativa profesionalización de la Administración pública en todos sus niveles se ha ido sustituyendo poco a poco por un sistema en el que la provisión de numerosos puestos de trabajo, con la excusa de su "especial responsabilidad y confianza", se realiza con criterios puramente partidistas. Lo más grave, por lo que ahora interesa, es que este fenómeno de colonización y fagocitación no se detiene aquí, sino que se apodera incluso de los más altos órganos de control, invadiendo la política de nombramientos e incluso los órganos de gobierno del poder judicial. En definitiva, en los países en los que se carece de cultura institucional profundamente arraigada, el sistema de separación de poderes como sistema eficaz de control del poder por el poder tiende a difuminarse y debilitarse de manera alarmante.

\subsection{Las tentaciones de la globalización económica para el Estado Social y Democrático de Derecho}

Otro fenómeno social con amplias repercusiones negativas en la separación de poderes es lo que Levinson denomina la captura del poder por la riqueza organizada $^{36}$. En sociedades donde tienen el suficiente poder, las élites económicas pueden captar por igual a los partidos que se disputan el poder de las instituciones. En esos casos, da igual cuál de ellos tenga el control de cada poder en cada momento, ya que ninguno de esos partidos hará nada significativo por cambiar las políticas económicas vigentes en aquello que beneficie a los intereses de la riqueza organizada.

Ante un panorama tal, además, esta captura de las instituciones por la riqueza organizada a través de los partidos políticos, plantea un escenario más sombrío aún. En efecto, en un contexto en el que la globalización de los intercambios comerciales no ha ido acompañada de una globalización de los derechos humanos, los poderes de los países dotados con un Estado social pueden experimentar un

${ }^{35}$ Sobre estos problemas, R. JIMÉNEZ AsENSIO (2016), 133-155.

${ }^{36}$ D. J. LEVINSON (2016), 85. 
paulatino retroceso en sus mecanismos de separación y control. Si esos poderes institucionales están puestos al servicio de intereses corporativos económicos, es fácil que experimenten una fuerte inclinación a debilitarse para acometer con mayor facilidad reformas restrictivas en materia de derechos fundamentales $y$ sociales. $Y$ ello porque, en un contexto así, dichas reformas pueden ser vistas como el único o el mejor camino posible para lograr el objetivo de producir a menor coste y concurrir en igualdad de armas con los países comercialmente más "competitivos", al precio lógicamente de desmantelar las instituciones del Estado social y democrático de derecho. Esta especie de emulación, por motivos económicos, de los países con democracias avanzadas respecto de los países sin dichos sistemas, puede acarrear a medio plazo nefastas consecuencias para la calidad de las instituciones políticas de aquellos.

\section{El impacto del plano social de la separación de poderes en las autoridades independientes}

Todo esto no sale gratis, evidentemente, y el propio Levinson ha llamado la atención sobre los efectos negativos que se derivan de estos fenómenos en el funcionamiento de las instituciones en general y de las autoridades independientes en especial. Estas últimas han surgido en parte como reacción a estos problemas, sobre todo al de la fagocitación de las instituciones por los partidos políticos. Y es que, como ha dicho Rachel E. Barkow, la independencia otorgada a estas autoridades administrativas persigue evitar los peligros propios de la politización, tales como las presiones para dar prioridad a intereses socioeconómicos sectoriales a corto plazo en detrimento del bienestar general a largo plazo ${ }^{37}$.

\section{I.Autoridades independientes y partidos políticos}

El peligro más tangible para estas autoridades proveniente del flanco del Estado de partidos es el de la designación de los correspondientes órganos directivos sobre la base de criterios total o predominantemente ajenos a la pericia motivada más bien por la conexión o sintonía del o de los candidatos con el partido político que ocupa el poder ${ }^{38}$. Aparte de la utilidad que, a estos efectos, puede reportar el

\footnotetext{
${ }^{37}$ R. E. BARKOW (2010), 19.

${ }^{38}$ Sobre el problema en España, puede verse M. SAlvador MARTínez (2015).
} 
fortalecimiento del perfil técnico exigible a los candidatos, mediante los oportunos procedimientos públicos de escrutinio, también se ha llamado la atención sobre las bondades que, en general, representa el que los órganos directivos de estas autoridades estén configurados como órganos colegiados, en lugar de ser órganos unipersonales. La ventaja de esta medida es que permite poner límites al número de miembros pertenecientes o elegidos por un mismo partido, evitando así la adopción por la autoridad independiente de decisiones extremas, de forma que se facilite una mayor estabilidad en la política de la autoridad. Diversas investigaciones empíricas han puesto de manifiesto que un cuerpo compuesto únicamente por personas de opiniones políticas o ideológicas afines tiende a la toma de decisiones extremas, más de lo que la media de las personas con las mismas opiniones decidiría ${ }^{39}$.

Por otra parte, de poco sirve objetivar el cese de los órganos directivos de estas autoridades por parte del poder ejecutivo si, al mismo tiempo no se toman otras precauciones adicionales. En concreto, sería demasiado ingenuo, máxime en un sistema parlamentario como el español, concentrar los esfuerzos por asegurar la independencia de estas entidades únicamente en relación con el poder ejecutivo. Como señala Barkow, concentrarse sólo en este aspecto resultaría insatisfactorio para evitar la captura y la presión política unilateral, ya que los grupos políticos o de interés pueden utilizar también la presión del legislativo para lograr ese mismo resultado ${ }^{40}$.

Esto es precisamente lo que ha ocurrido entre nosotros con la antigua Comisión Nacional de la Competencia, lo que revela que el establecimiento por ley de las garantías de inamovilidad de los órganos directores puede resultar una garantía demasiado blanda frente a los poderes legislativo y ejecutivo y la voracidad de los partidos que los dominan. Poco después de que el signo político del Gobierno y de las Cortes generales cambiara tras las elecciones de finales de 2011, se aprobó una ley mediante la cual la Comisión Nacional de la Competencia fue sustituida por una nueva autoridad, la Comisión Nacional de los Mercados y de la Competencia. Ello conllevó simultáneamente el cese de los órganos de dirección de la primera y el nombramiento de los nuevos órganos de la segunda, todo ello -por supuesto- sin que se llegaran a respetar los plazos que la ley de la autoridad extinguida señalaba para el mandato de dichos órganos directivos ${ }^{41}$.

39 Vid. R. E. BARKOW (2010), 40.

${ }^{40}$ Vid. R. E. BARKOW (2010), 26.

${ }^{41}$ Sobre el particular y, además, los problemas de compatibilidad que ello ha planteado en relación 
En este apartado hay que referirse también a un mecanismo sutil mediante el cual el legislador puede debilitar a la autoridad independiente de forma casi tan imperceptible como efectiva. Se trata de la paradóiica amenaza que para la independencia de estas autoridades podrían representar sus propias competencias en caso de ser éstas demasiado amplias. En efecto, desde la perspectiva de evitar la "captura" de la autoridad por otros poderes institucionales o fácticos, puede ser útil que la autoridad cuente con competencias amplias, de modo que la autoridad sea lo suficientemente fuerte como para resistir la presión de cualquier grupo de interés. Sin embargo, resulta clave en tal caso evitar que el organismo entre en conflicto consigo mismo porque el legislador le encomiende por un lado la promoción de determinada industria y, por otro, una misión de interés público general. En estos supuestos existe un riesgo claro de que la presión de la industria y los objetivos económicos a corto plazo, fácilmente medibles, se impongan sobre los objetivos públicos a largo plazo, más difíciles de evaluar.

En Estados Unidos, por ejemplo, existen estudios en los que se ha puesto de manifiesto cómo una autoridad reguladora, el Servicio Forestal, ha dado prioridad a la producción maderera en perjuicio de otras competencias suyas de interés general relacionadas con la conservación del medio natural. Fenómenos similares se han registrado en relación con otras autoridades independientes, en las que, a largo plazo, objetivos de interés general, como la protección del medioambiente, han sido sistemáticamente postergados en beneficio de objetivos de desarrollo económico ${ }^{42}$.

De nuevo, entre nosotros, este es el caso de la Comisión Nacional de los Mercados y de la Competencia, fruto de la unificación que operó la Ley $3 / 2013$ entre un buen puñado de organismos reguladores sectoriales y la antigua Comisión Nacional de la Competencia ${ }^{43}$. Así lo puso de manifiesto en su momento, por ejemplo, Baño León señalando que no parecía "una idea feliz unir en un mismo ente funciones diversas y potencialmente contradictorias, como es la regulación administrativa y la administración de la libre competencia" ${ }^{44}$.

con el Derecho de la Unión Europea, puede verse A. RaLLo LombarTE (2014).

${ }^{42}$ Vid. R. E. BARKOW (2010), 50 y 51.

${ }^{43}$ En concreto, la Comisión Nacional de la Energía, la Comisión del Mercado de las Telecomunicaciones, la Comisión Nacional del Sector Postal, el Comité de Regulación Ferroviaria, la Comisión Nacional del Juego, la Comisión de Regulación Económica Aeroportuaria y el Consejo Estatal de Medios Audiovisuales.

${ }^{44}$ J. M. BAÑo LEÓN (2013), 1259. 
Finalmente, otro punto débil de las autoridades independientes suele ser el de su subordinación presupuestaria a los otros poderes. En Estados Unidos, por ejemplo, entre 1993 y 2001 la Securities and Exchange Commission, según declaraciones de uno de sus antiguos presidentes, se vio constantemente amenazada con recortes presupuestarios por parte del Congreso en caso de aprobar regulaciones especialmente exigentes. La solución a este problema (por ejemplo, en Estados Unidos en relación con la Reserva Federal) ha consistido en proporcionar a las autoridades una fuente de financiación alternativa, a través -por ejemplo- del pago obligatorio de honorarios a la autoridad independiente. El problema, sin embargo, se traslada a los propios operadores económicos, que satisfacen dichos honorarios y que pueden capturar indirectamente por la vía de elegir a la autoridad independiente supervisora ${ }^{45}$. En estos casos habría que idear, entonces, otros mecanismos de financiación, en la línea-por poner un caso- de establecer un fondo común, en el que se paguen los honorarios y luego se repartan entre las autoridades supervisoras correspondientes; o destinar un porcentaje fijo de los impuestos recaudados, tanto a los grupos económicos como a los no económicos o más débiles, para la financiación de las autoridades independientes reguladoras de ese sector.

\subsection{Los peligros de captura por la "riqueza organizada"}

En relación con esto último, las autoridades independientes están expuestas también a la presión directa de lo que hemos denominado la "riqueza organizada". En Estados Unidos, por ejemplo, hay estudios en los que se evidencia la sobrerrepresentación de los intereses sociales o económicos regulados en los procedimientos de decisión de las autoridades independientes. Las razones son diversas. En primer lugar, porque las industrias reguladas están bien financiadas y bien organizadas, especialmente en comparación con los ciudadanos en general. De ahí que los grupos industriales estén mejor posicionados para vigilar la actividad de las autoridades independientes e impugnar cualquier decisión de estas que les afecte negativamente. Y como las autoridades independientes prefieren, por lo general, no quedar atascadas en laberintos legales, sienten con frecuencia la inclinación de trabajar "con", en lugar de "contra", esos intereses sociales y económicos fuertemente organizados. Aunque algunos grupos importantes e influyentes buscan representar el interés de los ciudadanos, estos grupos de interés no cuentan con la financiación o los recursos de la industria. Por lo tanto, a menudo no pueden controlar y recurrir todas las decisiones potencialmente negativas de la autoridad independiente. Existe aquí un claro desequilibrio entre intereses. De ahí que, desde

${ }^{45}$ Vid. R. E. BARKOW (2010), 45. 
muy pronto, en Estados Unidos se acometiera la tarea de profundizar en el régimen de estas entidades hacia una mayor transparencia, garantías procedimentales (otorgando una legitimación más amplia a los ciudadanos) y mecanismos de participación ciudadana ${ }^{46}$.

También es conocido el sutil proceso de captura del regulador a través del denominado fenómeno de "puertas giratorias": las posibilidades de los directivos de la autoridad independiente de volver a ser empleados por el sector económico regulado una vez terminados sus mandatos, genera, evidentemente, la inclinación en ellos a no aprobar regulaciones rigurosas a fin de no granjearse enemigos dentro de ese sector. En tales casos, la solución puede consistir en extremar las exigencias en el perfil técnico de los candidatos a nombrar, así como añadir otros requisitos como carecer de acciones en el sector económico que se trata de controlar, etc. Estas medidas pueden ir acompañadas de la prohibición de trabajar en el sector regulado con posterioridad al cese, lo cual debe hacerse con ciertas dosis de prudencia, porque los costes que ello conlleva pueden desincentivar a los especialistas altamente cualificados a prestar servicios en las autoridades reguladoras. Por tanto, la prohibición debe combinarse con plazos de prohibición que sean adecuados y retribuciones que compensen suficientemente dichos costes ${ }^{47}$.

En cualquier caso, todas estas prohibiciones, exigencias, límites y requisitos deben estar respaldados por un aparato coactivo o sancionador que sea eficaz y creíble. A este respecto, la legislación española, aunque ha dado pasos en la buena dirección, sigue presentando lagunas y deficiencias difícilmente aceptables. Por ejemplo, de nada o de muy poco sirve que la Ley de Buen Gobierno, del año 2013, haya establecido un catálogo de infracciones y sanciones disciplinarias en la materia, dirigidas específicamente a los altos cargos, si el órgano competente para exigir (prácticamente de forma discrecional) esa responsabilidad es el propio ejecutivo que los nombró o propuso para su designación.

${ }^{46}$ Vid. J. Solanes Mullor (2016), 66 y 67, 321 y 322.

${ }^{47}$ Vid. R. E. BARKOW (2010), 48 y 49. 


\section{Una mirada al sector financiero y al Fondo de Reestructu- ración Ordenada Bancaria (FROB)}

\section{I. Del esquema del "concurso" al de la "reestructuración"}

Decía el Código de Comercio español de 1829 que se considera en estado de quiebra a todo comerciante que sobresee en el pago corriente de sus obligaciones. Con ello se aludía al núcleo de toda situación de insolvencia empresarial, una situación caracterizada por la incapacidad económica de la empresa para cumplir las obligaciones contraídas con otros sujetos, en su mayor parte también empresas. Se establece a partir de ese momento una relación conflictiva múltiple entre el interés del deudor común (la empresa en quiebra) y la pluralidad de los acreedores, que concurren todos, para hacer efectivos sus créditos, sobre un mismo patrimonio -el del deudor común- que es insuficiente para satisfacerlos a todos íntegramente. En síntesis, la solución tradicionalmente adoptada ha sido la extinción de la propia empresa y la liquidación de su patrimonio entre la multiplicidad de acreedores conforme a determinadas reglas de proporcionalidad y preferencia.

En España ha sido asimismo tradicional que la declaración de tal estado de insolvencia y la determinación de sus consecuencias hayan estado atribuidas a los jueces. Y no por casualidad: recuérdese cómo la resolución de conflictos entre particulares ha sido atributo característico del poder judicial desde las primeras formulaciones del principio de separación de poderes.

Desde muy pronto, sin embargo, estas reglas han contado también con ciertas excepciones en algunos sectores económicos. Dicho régimen excepcional ha consistido, sobre todo, en evitar en lo posible la desaparición de la empresa insolvente cuando alguna razón de interés general lo justifique. Un ejemplo expresivo, entre otros muchos posibles, es el que ofrecía en la inmediata posguerra la Ley de 1 de septiembre de 1939, de Intervención de Empresas Mercantiles, en relación con las empresas que devinieran insolventes y cuya actividad mercantil, por su carácter estratégico (para la defensa, las comunicaciones o la energía), revistieren interés para el Estado.

Una característica muy importante de estas leyes de "intervención" -y en las que también se vio incluido el sector financiero desde antiguo- es que el poder competente para su aplicación no era de entrada el poder judicial, sino el poder ejecutivo. Ello seguía siendo coherente con la versión clásica del principio de separación de poderes, ya que la intervención pública prevista en esas leyes con- 
sistía únicamente en la sustitución temporal de los órganos de administración de la sociedad mercantil por el gobierno -o por sujetos nombrados por el gobierno-, sin incidir directamente (esto es, como poder público) en las relaciones (conflictivas o potencialmente conflictivas) entre la empresa y sus acreedores.

En el sector financiero este esquema es en esencia el que ha estado vigente también durante décadas. Pero por diversas circunstancias, como la creciente complejidad del sector y últimamente, sobre todo, la magnitud de los problemas de liquidez, solvencia y peligros de contagio planteados por la crisis financiera desatada a partir del año 2008, ha hecho que el modelo haya mutado profundamente en este ámbito ${ }^{48}$. Así, bajo la legislación vigente -a estos efectos, la aprobada sobre todo en los años 2014 y 2015- sigue existiendo, por supuesto, la intervención de las entidades financieras por el Banco de España, que entra en juego (como una de las medidas de lo que la ley llama "actuación temprana") cuando el nivel de solvencia señalado por las normas a este tipo de entidades desciende de tal forma que se pone en peligro la supervivencia de la entidad en cuestión ${ }^{49}$.

La principal novedad es que, a este mecanismo clásico de la intervención por autoridad administrativa, se ha venido a añadir lo que la ley denomina resolución de entidades de crédito. Esta última consiste, además de en la intervención-que también se contempla como parte de la resolución-, bien en la reestructuración, bien en la liquidación ordenada de la entidad, cuando concurran tres circunstancias: que la entidad sea inviable o sea previsible que vaya a serlo en un futuro próximo; que no existan perspectivas razonables de que medidas procedentes del sector privado puedan corregir tal situación; y que por razones de interés público y estabilidad financiera resulte necesario evitar su "liquidación concursal", es decir, su liquidación por el poder judicial según las normas generalmente aplicables a cualquier empresa.

\footnotetext{
${ }^{48}$ Para una visión panorámica de la evolución del sector financiero y del papel Banco de España en las décadas anteriores, vid. A. Rodero FranganilLo (2003).

${ }^{49}$ Sobre dicho régimen, entre las obras inmediatamente anteriores a la reforma legal aludida, pueden verse las ponencias y comunicaciones contenidas en La regulación económica; en especial, la regulación bancaria. Actas del IX Congreso Hispano-Luso de Derecho Administrativo (Córdoba, 2010), coord. Manuel ReBollo PuIG, lustel, Madrid, 2012.
} 


\subsection{Las funciones atribuidas al FROB y su conexión con el interés general}

Precisamente esta última circunstancia es sobre la que interesa proyectar el foco de atención, ya que es la que afecta directamente a la separación de poderes. De la intervención como medida de actuación temprana, ya hemos indicado que la autoridad competente es el Banco de España. De la intervención como medida de resolución también se ocupa otra autoridad administrativa, el Fondo de Reestructuración Ordenada Bancaria (FROB), que es quien la decide y nombra un "administrador especial" en sustitución de los órganos de administración, directores generales o asimilados de la entidad intervenida.

Sin embargo, la resolución incluye medidas que van más allá de la intervención, que son competencia asimismo del FROB y que inciden directamente en las relaciones entabladas entre sujetos particulares en torno a la constitución de la entidad financiera o entre esta y sus acreedores. En concreto, el FROB puede imponer la venta de las acciones de la entidad a un tercero, la transmisión de determinadas categorías de activos especialmente dañados o cuya permanencia en los balances de la entidad puede ser perjudicial para su viabilidad, la recapitalización de la entidad mediante la conversión en capital de pasivos con eventual compensación a los acreedores, etc. Es decir, las actuaciones del FROB consisten, en buena medida, en la composición de una pluralidad de intereses potencialmente enfrentados con el fin de lograr la supervivencia de la entidad o, al menos, de su actividad en manos de una entidad distinta.

En realidad, por tanto, no hay en juego aquí intereses exclusivamente privados; la actuación del FROB se justifica en que, en los casos contemplados por la resolución de entidades financieras, subyace también un interés general, el representado por algunos de los objetivos enumerados por la ley para los procesos de resolución: la continuidad de actividades y servicios cuya interrupción podría perturbar la prestación de servicios esenciales para la economía real o la estabilidad financiera, evitar efectos perjudiciales para la estabilidad del sistema financiero, previniendo el contagio de las dificultades de una entidad al conjunto del sistema, y -puesto que algunas de las medidas de resolución se apoyan en la inyección de dinero público-asegurar la utilización más eficiente de los recursos públicos, minimizando los apoyos financieros públicos que, con carácter extraordinario, pueda ser necesario conceder (artículo 3 de la Ley 11/2015). 


\subsection{El FROB, ¿autoridad independiente?}

Así pues, puede afirmarse, sin mucha dificultad, que concurre el primer requisito para encomendar la composición de intereses privados en conflicto a un poder no judicial, esto es, al poder ejecutivo. Pero, ¿̇se caracteriza el FROB por las notas de independencia e inamovilidad que son necesarias para considerarlo como autoridad independiente? Lo cierto es que, aunque nombrado por el Gobierno, el Presidente del FROB dispone de un mandato no renovable de cinco años y sólo puede cesar por causas tasadas y predeterminadas por la ley, sin que el Gobierno goce de ninguna facultad discrecional al respecto. Además, se encuentra bajo la prohibición -general para los altos cargos- de prestar servicios profesionales a entidades afectadas por sus decisiones como presidente del FROB en los dos años siguientes a su cese como tal.

Pero también es verdad que dispone de muy pocas atribuciones ejecutivas. Casi todas las competencias decisorias del FROB y, desde luego, las más importantes, tanto en los procesos de actuación temprana como en los de resolución de entidades, recaen no en su presidente, sino en un órgano colegiado, la comisión rectora. Y esta comisión, en la que se integra también el presidente como uno más (aunque con voto dirimente en caso de empate), está compuesta de otros diez miembros: cuatro designados por el Banco de España (uno de los cuales es el subgobernador), el vicepresidente de la Comisión Nacional del Mercado de Valores, tres representantes del Ministerio de Economía (designados por el ministro) y dos representantes del Ministerio de Hacienda (designado también por el ministro).

En conjunto, puede concluirse que la independencia del FROB está muy difuminada y que difícilmente puede predicarse de él su carácter de autoridad administrativa independiente. En efecto, como puede verse, casi la mitad de los miembros de la comisión rectora -cinco de once- dependen directamente del gobierno. Y la otra mitad, quitando al propio presidente del FROB, dependen a su vez de otras autoridades, cuatro del Banco de España y uno de la Comisión del Mercado de Valores. El Banco de España -y en parte también la Comisión del Mercado de Valores- tiene, a su vez, importantes funciones de supervisión sobre las entidades financieras. A este respecto debe repararse en que, cuando los mecanismos de resolución encomendados al FROB se ponen en ejercicio, puede ser, en bastantes ocasiones, porque aquellas funciones de supervisión no han sido todo lo eficaces que deberían. Desde este punto de vista, atribuir al Banco de España, principal responsable de dichas funciones, un peso tan decisivo en el principal órgano de gobierno del FROB, puede suponer un lastre para el ejercicio imparcial de las funciones atribuidas a éste. 
Estas carencias tampoco se encuentran amortiguadas por una especial atención hacia otras exigencias del principio de separación de poderes en relación con las autoridades independientes. En concreto, sería deseable quizá un incremento en relación con la transparencia y mayores garantías en términos de procedimiento y participación ciudadana. Téngase en cuenta que de las decisiones del FROB depende en gran medida el nivel de recursos públicos a utilizar en la reestructuración de las entidades financieras, lo que se traduce a la postre en el monto de los presupuestos generales del Estado y en el nivel de presión fiscal ejercida sobre los ciudadanos. Desde este punto de vista, no resulta comprensible que la ley remita a un reglamento de régimen interno, a aprobar por la propia comisión rectora, las "reglas esenciales de su actuación" en el "ámbito procedimental", sin que la ley contenga al menos algunas determinaciones sustanciales sobre el particular.

Relacionado con estos aspectos, es lógico que la ley excluya, como cautela, la difusión de cualquier información relevante que pueda impactar negativamente en la entidad financiera cuando se estén preparando o realizando negociaciones para una actuación temprana o una resolución y, en particular, mientras se lleva a cabo la valoración de los activos y pasivos de la entidad en el marco de estas operaciones. Pero lo que carece de sentido es que, una vez superadas dichas fases, las decisiones adoptadas adolezcan de insuficiencias de motivación, como algún estudio reciente ha puesto de manifiesto en relación con el valor finalmente asignado a una entidad financiera que ha sido objeto de resolución empleando para ello grandes cantidades de recursos públicos ${ }^{50}$. De forma similar podría resultar inconstitucional el recorte -contenido en la ley- de las competencias de control del poder judicial sobre la valoración de activos y pasivos realizada por la autoridad en el caso de que ésta no hubiera sido expresamente invocada con ocasión del recurso formulado contra la decisión a la que acompañe ${ }^{51}$. En efecto, tal merma en las competencias del poder judicial a favor del Banco de España o

50 Vid. S. Climent-SerRano (2016), quien calcula el valor del Banco de Valencia antes de su resolución fijándolo en 4.042.244 millones de euros y planteando diversos interrogantes sin respuesta acerca de los criterios que empleó el FROB para venderlo a CaixaBank por un euro después de una inyección de 5.500 millones.

${ }^{51}$ Así podrían interpretarse, al menos, los términos ambiguos y confusos en que se expresa el artículo 72.2 de la Ley $11 / 2015$

La valoración que acompañe a los actos y decisiones del supervisor y de las autoridades de resolución competentes mencionados en el párrafo anterior, no podrá ser objeto de recurso separado, siendo únicamente impugnable en los recursos que se planteen contra aquellos actos y decisiones. Si no fuese impugnada, será utilizada por el tribunal como base de su propia evaluación de los actos o decisiones objeto del recurso contencioso-administrativo. 
del FROB puede estar reservando a favor de estos últimos un resquicio de poder exento de todo control, vulnerándose con ello-como hemos visto a lo largo de este trabajo- el principio de separación de poderes (además del derecho fundamental a la tutela judicial efectiva).

\section{Conclusión}

Un entendimiento actualizado del principio de separación de poderes exige que su compatibilidad con las denominadas administraciones o autoridades independientes vaya más allá de un enfoque puramente institucional y formalista, y atienda a la cuestión de si la aparición de estas instituciones es realmente necesaria y eficaz para asegurar el control del poder por el poder.

Desde este punto de vista, y a la luz de las consideraciones realizadas en el presente trabajo, puede afirmarse que, por las funciones que se le atribuyen, el $F R O B$ debe configurarse como autoridad o administración independiente. Sin embargo, la composición de dicho ente hace que su grado de independencia se sitúe en niveles más bajos de los que sería deseable, tanto en relación con el Gobierno como con otros organismos o autoridades independientes (sobre todo, Banco de España) que pueden suponer un lastre para su imparcialidad. También se detectan deficiencias en cuanto a la transparencia en sus procesos de toma de decisiones y en el alcance del control judicial sobre estas, así como -y esto es común al resto de las instituciones- en relación con la eficacia del régimen disciplinario previsto para los altos cargos y su prevención frente al fenómeno de "puertas giratorias".

\section{Bibliografía}

ARIÑO ORTIZ, G. (2010) "El control judicial de las entidades reguladoras: la necesaria expansión del Estado de Derecho": Revista de Administración Pública 182, 9-37.

Artola, M. (1999) "Estudio Preliminar" a Agustín ArgüElles, Examen Histórico de la Reforma Constitucional de España (1835), Oviedo, Junta General del Principado de Asturias.

Baño LEÓN, J. M. (2013) "Libre competencia y Administración Pública: Derecho Administrativo y Derecho "antitrust»", en Derecho de la Regulación Económica. IX. Comercio Interior, Tomo II, dir. Manuel ReBOllo PuIG, Madrid, lustel, 1.203-1.259. 
Barkow, R. E. (2010) "Insulating Agencies: Avoiding Capture Through Institutional Design": Texas Law Review 89, 15-79.

Bueno Armijo, A. (2014) "Recensión al libro La tutela administrativa de la propiedad intelectual en la sociedad de la información, de Manuel RodríGuez Portugués", Revista Española de Derecho Administrativo 161, 413-420.

Carpintero Benítez, F. (1989) La cabeza de Jano, Cádiz, Servicio de Publicaciones de la Universidad de Cádiz.

Climent-Serrano, S. (2016) "¿Quién paga, quién gana? El caso de la venta del BdV": European Research on Management and Business Economics 22, 47-54.

Hamilton, A., MADISON, J. y JaY, J. (2015) El Federalista, traducción de Daniel BLANCH y Ramón Málz, Madrid, Akal [título original: The Federalist: a Collection of Essays, written in favour of the New Constitution, as agreed upon by the Federal Convention, 17-IX-1787].

Jiménez Asensio, R. (2016) Los frenos del poder. Separación de poderes y control de las instituciones, Madrid, Marcial-Pons.

LEVINSON, D. J. (2016) "Looking for power in Public Law": Harvard Law Review $130,1,33-143$.

LOCKE, J. (32014) Segundo Tratado del Gobierno Civil, traducción de Carlos Mellizo, Madrid, Alianza [título original: The Second Treatise of Civil Government. An Essay Concerning The True, Original, Extend and End of Civil Government, 1690] .

López Martín, M". C. y Rodero Franganillo, A. (2009) "Las finanzas y la crisis económica y financiera": Revista de Fomento Social 64, 687-698.

MONTESQUieu, C-L. S. B. de (1987) Del Espíritu de las Leyes, traducción de Mercedes Blázquezy Pedro de Vega, Madrid, Tecnos [título original: Del'Espritdes Lois, 1735].

MuÑoz MACHADO, S. (2015) Tratado de Derecho Administrativo y Derecho Público General, Tomo II, Historia de las Instituciones jurídico-administrativas-2, Madrid, Boletín Oficial del Estado.

Rallo Lombarte, A. (2014) "La Comisión Nacional de los Mercados y la Competencia: los reparos de las instituciones europeas sobre la independencia del regulador": UNED-Teoría y Realidad Constitucional 34, 193-234. 
RIALS, S. (1988) La déclaration des droits de l'homme et du citoyen, París, Hachette.

Rebollo PUIG, M., coord. (2012) La regulación económica; en especial, la regulación bancaria: actas del IX Congreso Hispano-Luso de Derecho Administrativo (Córdoba, 2010), Madrid, lustel.

Rodero Franganilo, A. (2003) "Los cambios del sistema financiero durante las dos últimas décadas": Revista de Fomento Social 58, 743-753.

RodríGUez PoRtuguÉs, M. (2013) "Reserva de jurisdicción, potestad reglamentaria y propiedad intelectual": Revista de Administración Pública 192, 231-256.

Salvador Martínez, M. (2015) "Partidos políticos y "autoridades independientes»": Revista Española de Derecho Constitucional 104, 83-99.

SOLANES MULLOR, J. (2016) Administraciones independientes y Estado regulador. El impacto de la Unión Europea en el Derecho Público español, Madrid, Congreso de los Diputados.

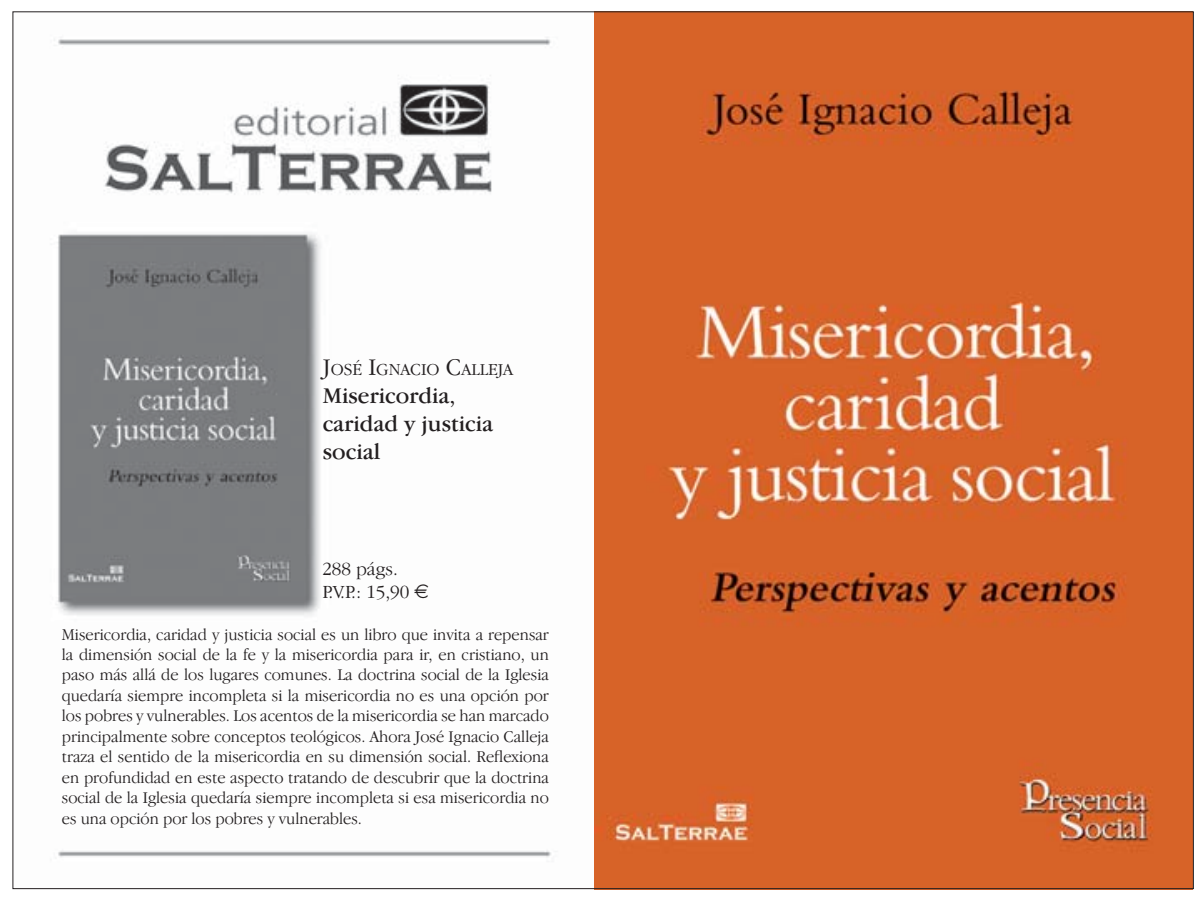

